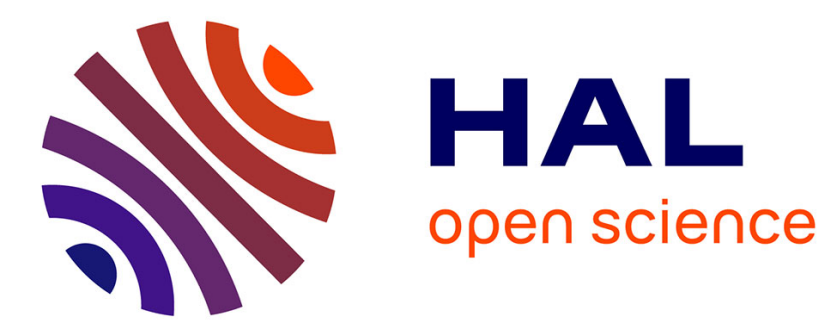

\title{
Towards a cognitive media genetics
}

\author{
Marcin Sobieszczanski
}

\section{To cite this version:}

Marcin Sobieszczanski. Towards a cognitive media genetics. Métamorphoses numériques,: Art, culture et communication :, coll. Communication et Civilisation, L'Harmattan, 2017. hal-01671163

\section{HAL Id: hal-01671163 \\ https://hal.science/hal-01671163}

Submitted on 22 Dec 2017

HAL is a multi-disciplinary open access archive for the deposit and dissemination of scientific research documents, whether they are published or not. The documents may come from teaching and research institutions in France or abroad, or from public or private research centers.
L'archive ouverte pluridisciplinaire HAL, est destinée au dépôt et à la diffusion de documents scientifiques de niveau recherche, publiés ou non, émanant des établissements d'enseignement et de recherche français ou étrangers, des laboratoires publics ou privés. 


\section{Towards a cognitive media genetics}

by Marcin Sobieszczanski

$31 / 08 / 2017$

\section{Table of Contents}

Abstract

Introduction

Genetics of the brain and its products 3

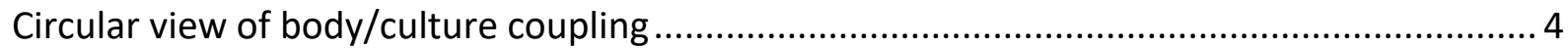

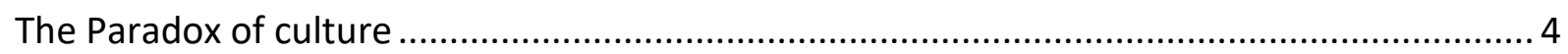

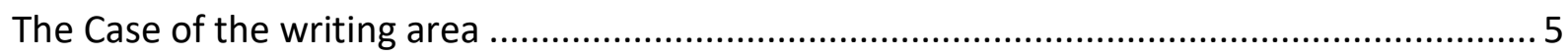

The Extension of the grammatological research ................................................................ 7

From "media genetics" to "pro-genetics of media design" ................................................. 8

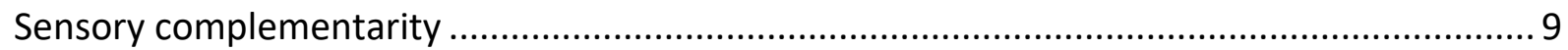

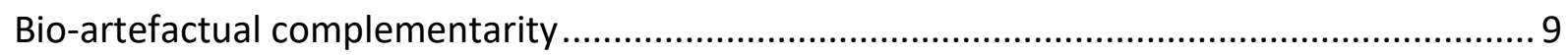

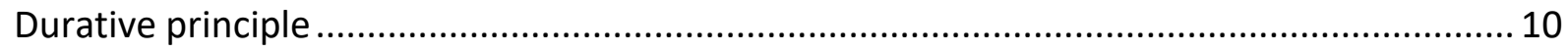

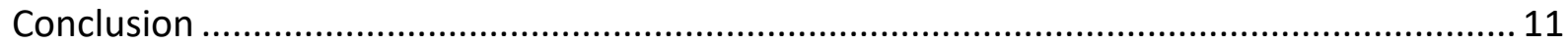

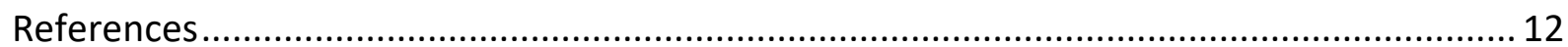

\section{Abstract}

The cognitive sciences have provided crucial insights into several fields of cultural sciences. In particular, the faculty of language has been the area of spectacular advances which have produced arguments in favor of a naturalized vision of linguistic artifacts. It is now the turn of writing, the first complex medium of the human being to seal the union of verbal language with a system of graphic signs, to be subjected to the application of biological epistemology and thereby to confirm the existence of bridges between the genetics of the brain substrate, epigenetics, behavioral mimicry and finally cultural learning. The cerebral localization of the 
scriptural abilities, recently discovered in the area known as the Exner area, argues for this body/culture circularity and makes it possible to imagine new research programs covering all the media. The diffusion of digital multisensory media brings a new element to this perspective. Indeed, the intensive use of these media causes an ultrafast impact on the functional architecture of the human brain. This new situation, in which the learning of a new medium and the cognitive impact that its use arouses, coincides with the process of its conception and circulation, confers on designers the role "pro-geneticists".

\section{Introduction}

In the late 1990s, the French information and communication science sector, through the researchers associated with the GIS "Sciences de la cognition", who include the present author, working under the direction of Gabriel Ganascia (Trognon, A., 1995) and in collaboration with Bernard Conein, began to draw conclusions from the cognitivist studies published in the Anglo-Saxon tradition summarized admirably in the posthumous work of Gregory Bateson (Bateson, G., 1991). First and foremost, the commitment was made, following the American colleagues, to consider the neural substrate that is at work in the background of every communicative act. An original contribution was also added: with the English translation of Dan Sperber and Deirdre Wilson (Sperber, D., Wilson, D. 1989), the concepts of cognitive effort and cognitive effect, in their turn crossed the Atlantic. However, the low presence of cognitive studies in current academic information and communication sciences (ICS), and even in media studies, confirms a certain slowdown in this field, and this at a time when the results of the cognitive sciences are at their peak.

Contrary to the techniques of visual and filmographic representation, linguistic and even literary studies or studies in social cognition, communication and information science are still looking for a cognitive object which would demonstrate to the public the relevance of a "characterized" or even "reductionist" epistemology, which these disciplines always rejected in the name of their hybridity and their polygenesis. This is surprising, as ICS have never been as close to the emerging cognitive sciences as they were in their own early stages. The present consequences of these old connections can still surprise us: the current global circulation of ideas around this premonition of Bateson testifies to this: 
"But let us suppose that in biological evolution there were a direct communicational bond between individual experience which will induce somatic change, as it's called, and the DNA injunction to be passed on to the next generation." (Bateson, G., 1991).

\section{Genetics of the brain and its products}

The exegesis of the Batesonian formula is obvious: firstly from Descartes, afterwards from the pioneering works of the Enlightenment naturalists, and finally with the rise of neurophysiology in the 19th century, a biunivocal correlation is postulated between the set of vital functions of species with nervous systems and the different populations of neurons implementing different cognitive functions, sometimes in a centralized way and every so often in a distributed way. The birth of genetics, which first appeared in Gregor Mendel's studies of the somatic characters, soon led to the question of the heredity of the nervous system. In general, since the arrival of the so-called "Weismann barrier" hypothesis (Weismann, A., 1892) at the end of the 19th century, the inheritance of individual variability has been called into question. The biological tissues present a fundamental differentiation between the so-called germinal cells and the somatic cells. The "barrier" functions here as a mechanism for preserving the morphological stability of multicellular organisms in the time required for the stabilization of their different species.

Moreover, in this vision, the nervous system still contains an additional level of complexity, since it is both a neurophysiological substrate implementing functions and a mechanism for acquiring, storing and processing the information generated in ecological experiments lived by individuals and by populations. If the "Weismann barrier" is a means of delay aimed at the genetic material to avoid impregnation by the somatic experience, it must be even more effective in the case of information affecting the nervous system. This "epistemological barrier" gives birth to a long tradition of separation between "somatic biology" and "psychological contents". It will be observed that this is also the dividing line, still current, between the so-called sciences of nature and the sciences of culture. Thus the classification of our sciences by fields does not solely rest on the kinds of objects of interest on which the "sciences of nature and life" and "sciences of human culture" are focusing, but also on the genetic means of transgenerational transmission of the mechanisms dedicated to the management of experiments relating to the ontogenesis of the individual and populations of biological individuals. 
Today, in the academic world, this schism is still alive and well, but research, both fundamental and applied, and perhaps above all the latter, seems already to be founded on a new epistemological basis. This can be observed on both sides of the disciplinary boundary.

\section{Circular view of body/culture coupling}

In the field of molecular and genetic biology, the critical resurgence of August Weismann's seminal ideas began with the thinking initiated in the late 1980 s by the American biologist and eco-philosopher Leo W. Buss (Buss, L., W 1987), and today it goes as far as the intracellular mechanisms to obtain a more fluid view of the relationships between heredity and experience (Radzvilavicius, A., L., Hadjivasiliou, Z., Pomiankowski, A., Lane, N., 2016). We also have a new vision of the molecular origin of the nervous system (Moroz, L., Kocot, K., M., Citarella, MR, et al., 2014) which, by observation of the multicellular organisms among the oldest sections of the population, comes closer to elucidating the way in which the aggregates of nerve cells manage their morphological stability, their heredity and the impact of ecological events on the individual organism as an "innervated body."

In the field of human cultural production, several pieces of research initiated in the 1990s demonstrate the importance of the evolution of behaviors and the evolution of cultures in the universal evolution which encompasses them in its enlarged, neo-Darwinian form, including both genetic and epigenetic mechanisms. A further step would be the questioning of the principle of the oneness of ontogenetic learning in the transgenerational transmission of language, as already envisaged in 1973 by Noam Chomsky (Chomsky, N., 2007), and of cultural goods... In other words, if, as Jablonka and Lamb maintain, culture is a powerful and autonomous vector of evolution in Humans, culture itself must be equipped with a biological mechanism enabling it to manage the evolution of the neuronal substratum which supports and produces it (Jablonka, E., Lamb, M., 1995). This quadridimensional circularity of the evolution of living organisms, genetic, epigenetic, behavioral and cultural, is even more obvious since the origins of culture had been observed earlier in the animal world (Lestel, D. 2009) including invertebrates (Avarguès-Weber, A., 2010).

\section{The Paradox of culture}

The genetics of culture also teaches us to proceed on the basis of a paradox. On the one hand, we attest in social insects "cultural" learning mechanisms (Avarguès-Weber, A., 2010) as 
evidenced by the extra-genetic transmission of the behaviors thus induced. On the other hand, we observe a long maturation of different parts of the brain, starting from the animals with consciousness (Anceau, F., 1999), through several stages of the development of the cortex and finally the arrival, in Humans, of "cerebral organs", such as "linguistic areas", dedicated to the production and communication of cultural objects. The paradox consists in the fact that many cultural productions, although taking advantage from the inputs of highly organized and specialized areas, take their birth in the polyvalent areas and even often can be considered as the result of a neuronal substrate which is mobilized ad hoc.

If, for example, no cerebral structures that support the practice of the visual arts which resulted from the establishment in the middle of the 18th century of the western system of the fine arts (Alain, 1920) have been observed, neurolinguists have observed successfully the advent of localized wave phenomena characterizing the production of utterances, according to the rules of grammatical generativity and in precise and repeatable deictic circumstances. This is not surprising given the respective age of these two cultural practices. Now, two facts erode any false certainties in this area. First, visual arts practices are systematically accompanied by linguistic artifacts. This co-presence must necessarily involve an intracerebral communication activity which ensures its coherence. Secondly, the fine arts system, as codified in the writings of Charles Batteux (Tatarkiewicz, W., 2012), was socially inculcated by an education practiced almost immutably during two centuries, and benefited from the authority of the circuit of consecration instances (Bourdieu, P., 1979). It has produced a veritable "Western aesthetic brain" which, operating through formal or private criticism, expresses itself in the place of the authority of "taste" and which in statistical studies gives substantially the same qualitative results as the "grammaticality" tests conducted with different populations of Western speakers (Piotrowski, D., 2005). Do we then have two cultures, verbal and visual, coming from two fundamentally different neuronal substrates, but ultimately leading to the same consequences? Here is the enigma of culture which calls the cognitive sciences to the aid of most contemporary cultural studies.

\section{The Case of the writing area}

On this level, the discovery, by the INSERM team "Brain Imaging and Neurological Disorders" at Toulouse, of the amazing characteristics of the "writing zone" offers particularly illuminating insights. As a field of psycholinguistics, this research outlines most interesting 
relationships between the neural substrate, cultural abilities and their modes of social propagation and transgenerational transmission. The empirical studies by INSERM, conducted with subjects undergoing surgery with the brain awake, during which they are given writing exercises, challenge us in various ways. Since the emergence of systemic studies on the evolution of writing, introduced in the 1960s by Ignace Jay Gelb (Gelb, I., J., 1963) and extended to the present day by Peter T. Daniels (Daniels, P., T., Bright, W., (ed.), 1996) grammatology espouses simultaneously two paths, the one, oriented towards language, which focuses on the progress made by different forms of writing in their way of representing graphically the phonological material, and that, oriented towards the graphic, which concentrates on the evolution of the capacities of the visual sign to represent the communicative intentionality of the Human. It is obvious that the second way highlights the medial aspect of writing. In essence, writing is a technical support of the communicated contents, and beyond its role of storage of the phonological material, it organizes above all the transfer of complex verbal entities by means of visual artefacts. The focal point for these studies is thus located within the cognitive ergonomics of the visual sign which ensures the intelligibility of verbal occurrences in the process of their communication. In this sense, the natural extension of this work can be applied to different media, their learning and their expansion, with, on the horizon, the redesigning of studies in media ergonomics and media design.

If articulated language is a "natural medium", in the sense that the arrangement of signifying matter, the indexing of the "content form" to the "content substance", according to Louis Hjelmslev's terminology, occurs, in the generations of Humans, simultaneously with the elaboration of the sound substance, writing is an "artefactual medium" in which the doubly articulated language system is "spliced" onto the graphical system resulting from a parallel but independent evolution. The evolutions of two sensory modalities will only be codependent after their union, from the invention, progressive and geographically dispersed, but rapid on the scale of hominization, of the media presenting a new mixed ergonomics.

The foundation and functioning of the "writing zone" (Roux, F.-E., Dufor, O., Giussani, C., Wamain, Y., Draper, L., Longcamp, M. Demonet, J.-F., 2009) highlighted six years ago by the team of Professor Démonet constitutes here a casus rationis which can be counted among the most important. We discover that a 6000-year-old activity, and in its alphabetical version only 
of 3800 years (Lemaire, A., 2008; Petrovich, D., 2016), which is transmitted through cultural learning, retains in the human brain an area dedicated to the association of the sound image with the motor pattern in charge of the execution of the corresponding grapheme. However, this area, known as the Exner zone (Exner, S., 1881), is not a cerebral organ in the sense of Broca and Wernicke.

The latter, attested in the endocranial casts carried out by Phillip Tobias (Tobias, P., V., 1991), date from the homo habilis, and constitute the neural substrate capable of taking charge of the learning of first facial, postural and gestural language, and then sound language, a process spanning between -2 million and -10000 years. They are therefore the somatic result of culture-driven evolution, and their functioning has lasted long enough to cross the "Weismann barrier" and form a part of the DNA components responsible for their complex architecture.

The Exner zone does not have the same age and does not present the same level of complexity, but it nevertheless systematically implements the learning of writing. We can postulate that the arrival of the graphic writing medium instead of resulting from the basic genetic processes is rather accompanied in time by a blend of epigenetic processes and processes of cultural transmission (Jablonka, E., Lamb, M 1995; Jablonka, E., Lamb, M., 2005). It is in the light of this combination that we must think of the media and of their participation in the circularity (biofeedback) that man engages in with his environment through the media. This is also where the limitations of the philosophy of bio-inspiration appear, something which requires now the consideration of the impact of the mix epigenetics/culture on the biological substrate, the impact that imposes a new source of inspiration for researchers and designers: the bio-artefactual one.

\section{The Extension of the grammatological research}

Jean-François Démonet and his former team in Toulouse propose diversifying their research by extending it across the various modes of technicized writing and most especially with the aid of the computer. The extrapolation of this program, its application to other media, would then propose an unheard-of protocol, both theoretical and operative, which would contain the following basic premise: 
- There is a neural substrate supporting the invention and the exercise of each artefactual medium. This substrate is a "fast-onset" substrate, derived from neuronal plasticity.

- In the process of the maturing of the media there occurs a threshold effect, when the brain reaches the optimum level of sensory ergonomics that the media offers.

- The media effect would be propagated by acculturation as an imitation of behavior and would be subject to transgenerational transmission through the process involving, through different timeframes, genetics, epigenetics, imitation of behavior and cultural learning.

- In as far as some temporalities of this "media genetics" take effect simultaneously with the process of design, industrialization and the social circulation of the media, the designer/researcher of the new media adopts indeed the function of actuator of the threshold cerebral effects and may consider this instance both as an inspiration area and as a field of bio-artefactual intervention. This kind of creative activity will be called the "living prototyping of media".

\section{From "media genetics" to "pro-genetics of media design"}

It is within this theoretical framework that we observe several current pieces of research in media design that incorporate the consideration of the bio-artefactual factor. We recognize these attempts by the joint presence of three procedures inherent to prototyping:

- Ecological modeling of communication acts taking into account the parallelism of different modal channels of communication.

- Modeling the bio-artefactual mix of the medial environment or taking into account the parallelism of the biological and artificial cofactors of medial context.

- The reiteration of prototyping at each stage of the media acculturation of the cognitive agents involved as actors in the trial.

We should note that these three procedures result from the adoption by designers of the modeling of the media as a complementary, creative side of the perceptual activity of the cognitive agent, the vision advanced in the field of theoretical research since the 1970 s by Robert Vallée (Vallée, R., 1995), president of the World Organization of Systems and Cybernetics (WOSC). 
This triple technological process is inspired by the ecological functioning of the media user and comes under what we call sensory complementarity, bio-artefactual complementarity and the durative principle.

\section{Sensory complementarity}

The epistemological principle of sensory complementarity seeks to discern the perceptual channels in which the interactivity between the psyche of the cognitive agent, the variable and evolutive characteristics of the medium and the environment in which the communication takes place. A decisive advance in this field has occurred since the discovery, in the early 2000s, of multimodal neurons concentrated in the "Geschwind Territory" composed of the angular gyrus and the supramargina gyrus, which simultaneously deal with the auditory, visual and somatosensory cortex, influencing at the same time the linguistic activities of the Human (Friedmann, M.-A., Siloni, T., 2007 ; Grodzinsky, Y., 2007).

This series of results of brain imaging confirms the hypotheses of the 1960s of the American neurophysiologist Norman Geschwind and puts media designers under the obligation to look for any ergonomic optimization in multisensoriality that is no longer only a coincidence of different modal fluxes but the condition of the excitability of large sections of neurons directly responsible for learning and practice of the media. Since the first intuitive application of this method on an industrial scale between 2003 and 2007, performed by Apple in the series of prototypes leading to the definition of the multimodal characteristics of the IPhone, designers have been working on the integration of its scientific bases in the very midst of the technological process, as shown by the program that remains at the heart of the patents involving Jonathan Ive (Jonathan, I.), the former collaborator of Steve Jobs and the new president of Royal College of Art in London.

\section{Bio-artefactual complementarity}

Since the environment of man today is strongly "anthropologized", the perceptual channels offer to each cognitive agent a sensory matter composed of a mixture of natural and anthropic factors. Research shows that the perception of sensory elements produced using different media provokes specific social cognition phenomena. The most spectacular example is cinematographic cognition. From the pioneering experiments conducted by the Center for Neural Science, New York University, in the field of neurocinematics (Hasson, U., Landesman, 
O., Knappmeyer, B., Vallines, I., Rubin, N., Heeger, D., J., 2008), we speak of "Inter-Subject Correlation in Brain Activity" (ISCiBA). This collective synchronization visible in MRI makes it possible to establish the neurofunctional distinction between the collective perception of the "raw" real and the reception of its filmographic representation structured in language. This paradigm of empirical research, inspired by David Bordwell (Bordwell, D. 2005) and continued today by the laboratory of Arthur P. Shimamura of the University of California Berkeley under the label of psychocinematics (Shimamura, A., P., (ed.), 2013) is however to be viewed with caution. Rather than pointing out the divergences between the different types of perception, the problem of the designer of the medial environments is to model the effective co-existence of heterogeneous stimuli. Discussion between bio-inspiration and bio-artefactual inspiration has become necessary to include in the conception of media the phenomena such as ISCiBA which, beyond the cinema, are omnipresent as soon as a medium covers a fragment of reality and in this way substitutes itself for certain parts of this reality. Each media that replaces the obsolete media never finds the same sequence of reality as that of its predecessor. On the contrary, the usage of the old media reconfigures the sensory richness in which the users evolve and it is this environment that is now the target of the designer.

\section{Durative principle}

The durative principle seeks to include the use of the media in the data present at its conception. This is not in order to predict a hypothetical ergonomics of the interface that the media should provide to the user or even less to demand a coercive study of existing ergonomics. The aim is to work at the confluence of epigenetic processes and processes of cultural transmission, considering the impact of learning, acculturation and use on the medial skills of the cognitive agent who has experienced the earlier phases of a media. The classic example is provided, in the area of the smartphone, by the coverage of different publics in 4G LTE networks. The city of Stockholm was equipped with it in 2009, in Seoul the tests began in 2008, in London in 2011 and Paris was covered in 2014. It is obvious that populations exposed to the use of media generated by $3 G$ are not the same as those accustomed to $4 \mathrm{G}$. In particular, all practices related to Application Programming Interface (API) have profoundly reconfigured the intellectual activities of the users. Some studies show that differences in cerebral function in intensive users can be detected by neurofunctional imaging within the four-year period (Lachaux, J.-P., 2011). If then the cycle comprising technological invention, 
patenting, industrial production and marketing is now on average seven years, this means that media designers have a neuronal substrate whose observable evolution includes the impact of the future media on which they are working. For researchers in the cognitive sciences, this substrate is indeed that which relates to a "characterized" or "reductionist" epistemology, but the operating field that it provides them is not reduced to the strict observation of a genetic process, it is indeed a "pro-genetics of media design" in relation to which the researcher and the designer take on the consubstantial role, that of stimulator.

\section{Conclusion}

In reviewing current research on the genetics of the nervous system and the diffusion of cultural products, we have observed a certain erasure of the disciplinary boundaries linked to the overcoming of the old epistemological dividing lines in the natural sciences. The evolution of the living world, and above all that of our species, would appear to be governed by four types of mechanisms, genetic, epigenetic, behavioral and cultural, between which one can observe a certain circularity or interdependence. On this basis the neuronal substrate of culture takes on a very particular meaning. In studying it, we do not only work on the discovery of its nature, but we influence de facto its causal dimension. The recent revisiting of the Exner area, where the cognitive skills resulting from the learning of writing are located, gives us an experimental paradigm that can be transposed, in our opinion, onto all media studies. But what is more, the quickness of the processes of maturation and evolution of the neuronal substrate engaged in the emergence of the media makes it possible to include their inventors in the profession of researchers. Indeed, designers of new media work not only from modeling of the neurophysiological processes involved in the process of invention but also actively participate in the evolution of these processes. Ecological multisensoriality, the parallelism of natural and anthropogenic factors, and finally the simultaneous temporalities of prototyping and of maturation of the neuronal substratum of the media, both conceived and studied, are conditions of this approach blending cultural genetics with living design.

This situation, where the "cognitive genetics of the media" catches up with its own determining factors, allows designers to raise awareness of the phenomenon and involve them in their own program of action. Through this pathway, they have the opportunity to work towards the realization of a social and individual brain ecology, which occupies the position of a mirror of the ecology of the communication channels of the environment, by the 
exercise and observation in real time of the ad hoc effects of the confluence of epigenetics and cultural transmission. The new "writing" is thus born before our eyes, the eyes of those who decipher it, and within the time of the achievement of its design.

\section{References}

Alain, 1920, Système des Beaux-Arts, Gallimard

Anceau, F., 1999, Vers une étude objective de la conscience, Hermes Science

Avarguès-Weber, A., 2010, Cognition visuelle chez l'abeille Apis mellifera : Catégorisation par extraction de configurations spatiales et de concepts relationnels, thèse, Université de Toulouse

Bateson, G., 1991, A sacred unity. Further Steps to an Ecology of Mind, A Cornelia \& Michael Bessie Book

Bordwell, D., 2005, Figures Traced in Light: On Cinematic Staging, Berkeley, University of California Press

Bourdieu, P., 1979, La Distinction. Critique sociale du jugement, Les éditions de minuit

Buss, L., W., 1987, The Evolution of Individuality. Princeton, New Jersey: Princeton University Press

Chomsky, N., 2007, Problèmes et mystères dans l'étude du langage humain, in Bricmont, J., Franck, J., (dir.), 2007, Chomsky, L’Herne

Daniels, P., T., Bright, W., (ed.), 1996, The World's Writing Systems, Oxford University Press Exner, S., 1881, Untersuchungen über die Localisation der Functionen in der Grosshirnrinde des Menschen. Vienna, W. Braumuller

Friedmann, M.-A., Siloni, T., 2007, Savoir inné et variation linguistique, in Bricmont, J., Franck, J., (dir.), 2007, Chomsky, L’Herne

Gelb, I., J., 1963, A study of writing. University of Chicago Press

Grodzinsky, Y., 2007, La syntaxe générative dans le cerveau, in Bricmont, J., Franck, J., (dir.), 2007, Chomsky, L’Herne 
Hasson, U., Landesman, O., Knappmeyer, B., Vallines, I., Rubin, N., Heeger, D., J., 2008, Neurocinematics: The Neuroscience of Film, in Projections. The Journal for Movies and Mind, Vol. 2, Issue 1, Summer 2008, pp.1-26, Berghahn Journals

Jablonka, E., Lamb, M., 1995, Epigenetic Inheritance and Evolution: The Lamarckian Dimension, Oxford University Press

Jablonka, E., Lamb, M., 2005, Evolution in Four Dimensions - Genetic, Epigenetic, Behavioral, and Symbolic Variation in the History of Life, MIT Press

Jonathan, I., http://patft.uspto.gov/netacgi/nph-

Parser?Sect1=PTO2\&Sect2=HITOFF \&p=1\&u=\%2Fnetahtml\%2FPTO\%2Fsearch-

bool.htm $\& \mathrm{r}=0 \& \mathrm{f}=\mathrm{S} \& \mathrm{I}=50 \& T E R M 1=i v e \% 3 \mathrm{~B}+$ jonathan \&FIELD1=INNM\&co1=AND\&TERM2=\&FI

\section{$E L D 2=\& d=P T X T$}

Lachaux, J.-P., 2011, Le cerveau attentif, Odile Jacob

Lemaire, A., 2008, The Spread of Alphabetic Scripts (c. 1700-500 BCE), Diogenes 218: 44-57

Lestel, D., 2009, Les origines animales de la culture, Champs

Moroz, L., L., Kocot, K., M., Citarella, M. R., et al., 2014, The ctenophore genome and the evolutionary origins of neural systems, Nature 510, 109-114, 05 June 2014

Petrovich, D., 2016, The World's Oldest Alphabet: Hebrew as the Language of the ProtoConsonantal Script (frontmatter), Carta

Piotrowski, D., 2005, Du sens en langue : aspects neurobiologiques, structuraux et phénoménologiques, Cahiers du CREA, $n^{\circ} 21$, Ecole Polytechnique

Radzvilavicius, A., L., Hadjivasiliou, Z., Pomiankowski, A., Lane, N., 2016, Selection for Mitochondrial Quality Drives Evolution of the Germline, Plos Bilogy, December 20, 2016 Roux, F.-E., Dufor, O., Giussani, C., Wamain, Y., Draper, L., Longcamp, M., Démonet, J.-F., 2009, Graphemic/Motor Frontal Area: Exner's Area Revisited, Annals of Neurology, July 2009 Shimamura, A., P., (ed.), 2013, Psychocinematics: Exploring Cognition at the Movies, Oxford University Press

Sperber, D., Wilson, D., 1989, La Pertinence, Communication et Cognition, Minuit, (2ème éd. an.) 
Sperber, D., Wilson, D., 1995, Relevance: Communication and Cognition, Blackwell

Tatarkiewicz, W., 2012, A History of Six Ideas: An Essay in Aesthetics, Springer Science, pp.116-117

Tobias, P., V., 1991, Olduvai Gorge. The Skulls, Endocasts and Teeth of Homo habilis, vols. 4A and 4B, Cambridge University Press, Cambridge

Trognon., A., 1995, Incidence de la situation de communication sur la cognition, in Ganascia, J.-G., 1995, Réflexion de prospective. Cognition et communication. Rapport préliminaire, http://www-poleia.lip6.fr/GIS.COGNITION/RP COC.html

Vallée, R., 1995, Cognition et système. Essai d'épistémo-praxéologie, L'Interdisciplinaire, Limonest

Weismann, A., 1892, Esais sur l'hérédité et la sélection naturelle, Reinwald 